\title{
IMPLEMENTATION OF ETHANOL HEAT PIPE AT CETIAT
}

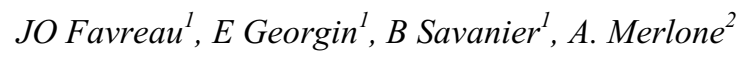 \\ ${ }^{1}$ CETIAT, 96100 Villeurbanne, France \\ ${ }^{2}$ INRIM, Torino, Italy
}

\begin{abstract}
CETIAT is a calibration laboratory accredited by COFRAC. The temperature generators are stirred calibration baths (from $-80{ }^{\circ} \mathrm{C}$ up to $+215{ }^{\circ} \mathrm{C}$ ), dry blocks and furnaces (from $-90{ }^{\circ} \mathrm{C}$ up to $+1050{ }^{\circ} \mathrm{C}$ ) and thermostatic chamber (from $-30{ }^{\circ} \mathrm{C}$ up to $+160{ }^{\circ} \mathrm{C}$ ). The best calibration uncertainty is achieved in calibration bath, for Platinum Resistance Thermometers (PRTs), it is $0.03{ }^{\circ} \mathrm{C}$. Nevertheless, the daily calibrations lead to an uncertainty about $0.06^{\circ} \mathrm{C}$ for industrial RTD sensors. The CETIAT is working on the implementation of a Gas Controlled Heat Pipe (GCHP) temperature generator to replace the thermometric baths in order to increase productivity and in order to improve temperature stability in the working volume of the generator. Many studies [1,2], explain the advantage of this method. For this purpose, the new system must have better thermal performance and produce the same temperature range than the stirred baths.
\end{abstract}

Two years ago, the CETIAT characterized a water GCHP for industrial applications cover the temperature range from $+30{ }^{\circ} \mathrm{C}$ up to $+150{ }^{\circ} \mathrm{C}$ [3]. The results were in good agreement with the expectations and water GCHP could be used to calibration production. But, we need to extend the temperature range towards the low temperatures. This year, the CETIAT characterized a new type of ethanol's heat pipe. We used the same heat pipe but this time we replaced water by ethanol. The possibilities of using ethanol, would allow generation of temperatures between $-40^{\circ} \mathrm{C}$ and $30^{\circ} \mathrm{C}$ low temperature enclosure.

\begin{abstract}
This article presents the first results on the study of a low temperature heat pipe made at CETIAT. The results obtained during the metrological characterization, in terms of temperature homogeneity and stability, in this study are encouraging. However, an issue with the stability of the cooling system diminish the quality of the results. The stability of the surrounding environment must be improved. This will be the subject of a future study. The results at $20^{\circ} \mathrm{C}$ are very positive. Over an axial length of $250 \mathrm{~mm}$, the thermal homogeneity is less than $5 \mathrm{mK}$.
\end{abstract}

\section{Introduction}

Heat pipes have been studied, manufactured and used since several decades for thermal applications, heat transfer purposes or industrial needs [4]. Gas Controlled Heat Pipes (GCHP) have been studied within these last twenty years, namely for metrological applications [5]. Among National Metrology Institutes (NMI) that are using GCHP, INRiM (Italy) has the most important background about it and could be considered as a reference institute for the GCHP technology. GCHP have been mainly developed for primary thermometry purposes $[6,7]$.

Heat pipes use the thermodynamic relationship between temperature and pressure in a fluid in liquid-vapour phase transition. GCHP use also this principle with a gas line that enables direct control of the inner pressure. Thus by controlling the pressure of the system it is possible to cover a wide range in temperature. From the
Clausius-Clapeyron equation and from the ideal gas law it comes:

$$
\frac{d T}{T}=\frac{R \cdot T}{M \cdot L} \cdot \frac{d p_{s a t}}{p_{s a t}}
$$

Where $\mathrm{R}$ is the universal gas constant, $\mathrm{T}$ the liquid vapour interface temperature, $M$ the molar mass of the vapour, $\mathrm{L}$ the latent heat of vaporization of the fluid that is used, and $\mathrm{p}_{\mathrm{sat}}$ the saturation vapour pressure.

From equation (1) it appears that any variations in pressure lead to a direct temperature change in the system. Thus, the internal temperature of the heat pipe can be regulated by a pressure variation. Furthermore, the main advantage of the heat pipe is to have a quasiadiabatic zone at its center. This is the thermally useful area for calibrations in terms of homogeneity and thermal stability. The object of this study is to check the thermal performance of this type of heat pipe.

Corresponding author: jacques-olivier.favreau@,cetiat.fr

C The Authors, published by EDP Sciences. This is an open access article distributed under the terms of the Creative Commons Attribution License 4.0 (http://creativecommons.org/licenses/by/4.0/). 


\section{DESIGN OF GCHP AT CETIAT}

The general design of the GCHP has been jointly done by INRIM and CETIAT, while realization and machining has been done by Criotec Impianti, a major gas and cryogenic systems manufacturer. The CETIAT GCHP consists in two main parts: the temperature generator (the heat pipe with ethanol) and the control circuit (buffer volume of 50 liters, pressure regulator). The figure 1, describe this different elements. On the right, in blue is shown the control circuit. It is composed with the heat pipe connected to the buffer volume to reduce the regulations problems (like overshoot). These elements are connected to the high precision pressure controller (PACE 6000) itself connected to the controller vacuum turbo pumping station (Adixen Drytel 1025). The other input is connected to pure nitrogen gas bottle (concentration is $99,995 \%$ ).

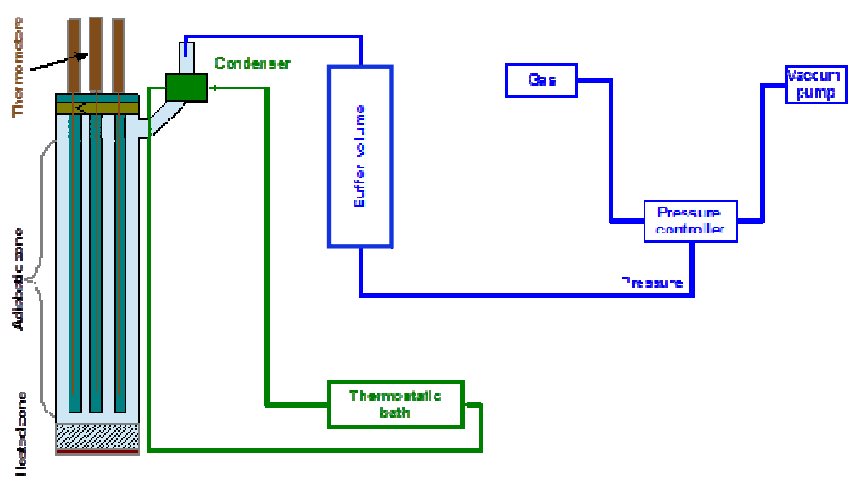

Fig. 1. Schematic diagram of GCHP

In the center of the figure 1 , in green is identified the cooling circuit with the stirred bath. The condenser is an important element, because it is used to condense the ethanol vapor to prevent it to go out of the heat pipe. On the left, in light blue, the useful part of the heat pipe, is the location where the probes to be calibrated (in brown) are introduced. It is a closed cylinder, made in stainless steel. The internal walls of the heat pipe are striated, allowing the liquid ethanol to flow by capillary action. At its top, it is connected to the pressure controller. When the heat pipe effect occurs, an adiabatic zone is created, in the central part, where the probes (in brown) to be calibrated are placed. In figure 2 , we can see a picture of the installation for the study. In order to reach low temperatures, we have set the GCHP in a low temperature enclosure.

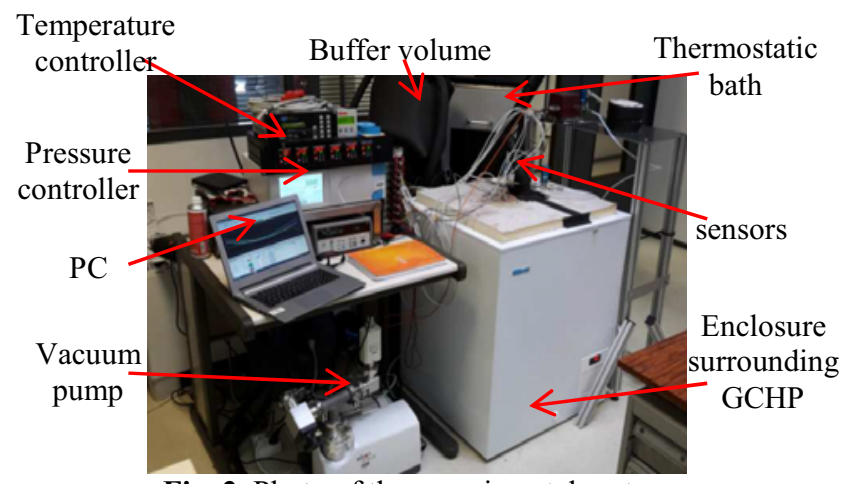

Fig. 2. Photo of the experimental system
For controlling the heating of the GCHP, as well as supervised the wall temperature, five sensors and heating elements are connected to a temperature controller. This makes it possible to obtain an ideal wall temperature to allow the heat pipe effect.

The recording system consists of a computer and data acquisition system (see fig 2). We use a Keysight 34972A data acquisition unit to connect nine characterization thermometers. This data logger switch Unit consists of a three-slot mainframe with a built-in 6 $1 / 2$ digit DMM (digital multimeter). The acquisitions are made every ten seconds. Measuring chains consisting of temperature sensors and multiplexer are calibrated in CETIAT's accredited thermometry laboratory.

Pressure control is ensured by PACE 6000 high precision GE pressure controllers \& indicators with a vacuum module. The working pressure range is between $400 \mathrm{~Pa}$ and $1 \mathrm{kPa}$, and the precision performance is $0.005 \%$ of measured value. The pressure controllers have been calibrated at CETIAT's laboratory. Therefore, the measurements are traceable to the International System of Units and all calibrations are performed under COFRAC (French ISO 17025 accreditation body) accreditation.

As described in [7], the design, that has been chosen, consists in a removable cover. This offers the possibility to change the fluid, such as water or ethanol. However, it is necessary to avoid damaging the internal walls, and also to avoid contamination of the internal part of the GCHP, during the filling operation. For this study, $250 \mathrm{ml}$ of ethanol have been introduced into the heat pipe after having drained, cleaned and dried of the other fluid. In the figure 3, we can see the level of ethanol in the heat pipe. It must be lower than the level of the thermal equalization block.

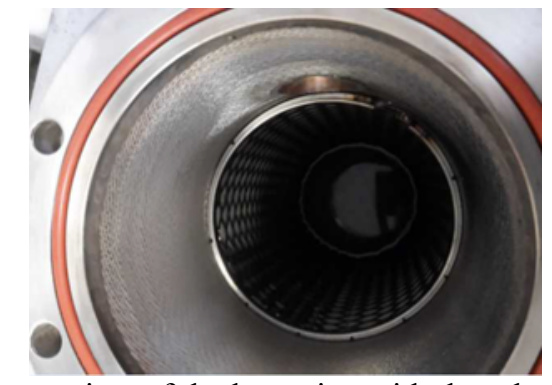

Fig. 3. Inner view of the heat pipe with the ethanol level.

The removable cover of the heat pipe is closed by 8 screws and an O-ring ensure the leak tightness. Then, it is composed of ten thermo-wells fixed on a thermal equalization block. We can see in figure 4 a schematic and a photograph of this cover. 

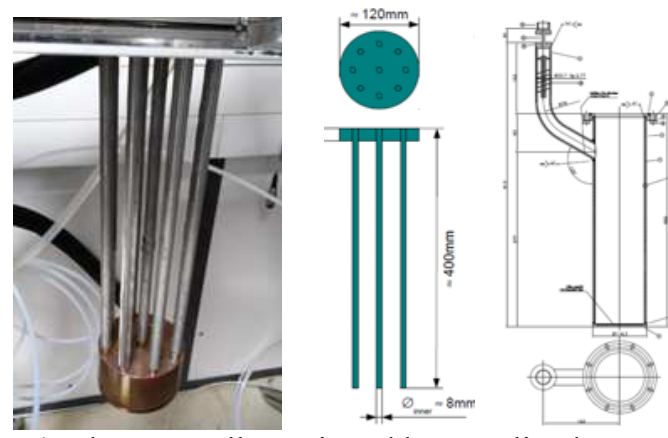

Fig. 4. Thermo wells equipped by equalization copper block.

In the photograph (fig 4), we can see the measuring tubes, the equalization temperature block in copper and the wire mesh around wells. The internal length of each measurement boring is $400 \mathrm{~mm}$. This corresponds to the depth of the calibration baths used in the laboratory. In this method, the sensors to be calibrated are introduced into the measurement wells without any thermal coupling.

In order to allow the heat pipe effect to occur in a volume, the ethanol has to be vaporized in the lower part. Then, the steam rises to the condenser and returns to the heating zone by gravity. In the central part of the heat pipe, the subsonic velocity of the vapour makes it possible to establish an adiabatic zone. The pressure and condensation settings make it possible to obtain a wide adiabatic zone. The pressure allows to work on a wide range of temperature. To initiate the heat pipe effect heating elements are fixed along the wall and at the bottom, to regulate the temperature. In the figure 5, we can visualize the different heating elements and their positions.

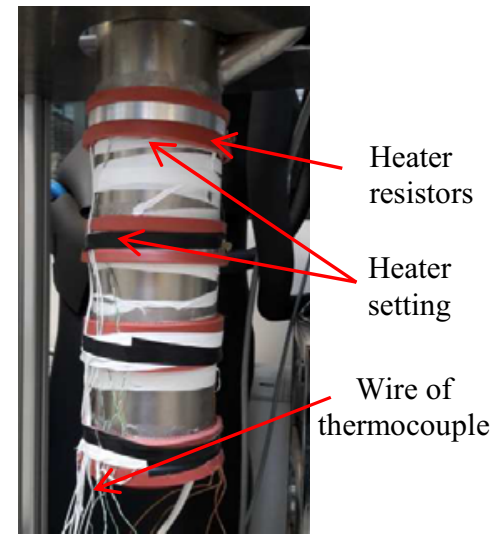

Fig. 5. Picture of heaters and thermocouples

The five heater resistors are fixed every five centimeter. A type $\mathrm{K}$ thermocouple is set in every heaters. These sensors make it possible to know the wall temperature of the heat pipe. Each heater zone could be controlled independently. This is important to optimize the settings.

CETIAT's GCHP is intended to be used from $-40{ }^{\circ} \mathrm{C}$ up to $+30{ }^{\circ} \mathrm{C}$, which corresponds to an internal pressure of $400 \mathrm{~Pa}$ to $1 \mathrm{kPa}$. Dry nitrogen is used for pressurizing the system and a vacuum pump to obtain a low pressure in the heat pipe. To work at low temperature and avoid condensation, the heat pipe is set inside low temperature enclosure. In the figure 6 , we can see the heat pipe with the fastening system. On the right, the condenser is visible. It is a copper tube which surrounds the exit chimney. The tube is connected to the circuit of an alcohol stirred bath. The insulation layer is placed on the condenser. The low temperature enclosure cover is placed on top, and the openings are thermally insulated (see fig 2).

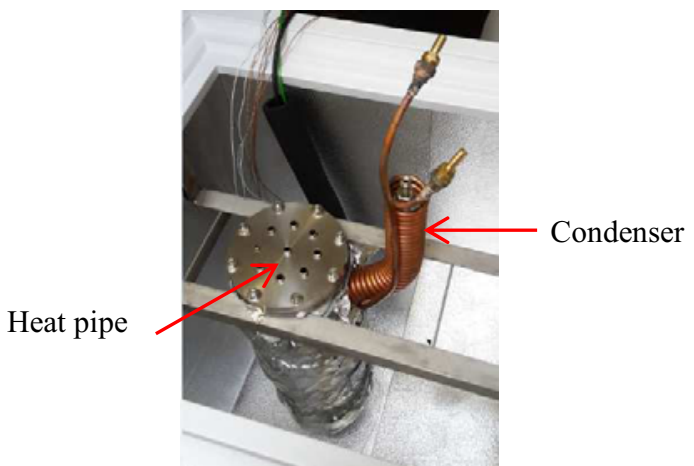

Fig. 6. Picture of the heat pipe inside the low temperature enclosure low temperature enclosure

\section{CHARACTERIZATION}

The results presented below show the surrounding enclosure of GCHP, the implementation of ethanol GCHP and the thermal characterization of the working volume in terms of homogeneity and stability.

\subsection{Thermal characterization of the low temperature enclosure}

The GCHP is housed inside an enclosure controlled in temperature. We use a standard laboratory low temperature enclosure. It is held by the lid to avoid thermal bridges (see fig 6).

The time response and thermal characteristics of low temperature enclosure are evaluated. It is a static low temperature enclosure without air flow. The dimensions of the Elcold low temperature enclosure type UNI 11 are shows in figure 7 .
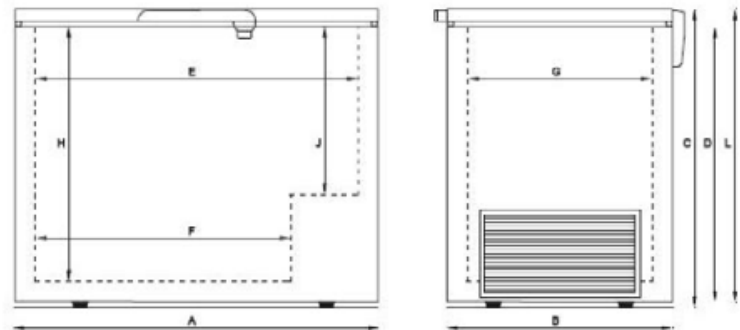

Fig. 7. Picture of the low temperature enclosure

The dimensions are $725 \times 860 \times 655 \mathrm{~mm}$. 
The cover assembly is thermally insulated to prevent condensation. In figure 8 , we can see the response curve of the low temperature enclosure at $-45^{\circ} \mathrm{C}$. The set time is about one hour but the thermal stability is not so good. The fluctuation's thermal amplitude is approximately $5{ }^{\circ} \mathrm{C}$. This point will be improved within the next steps.

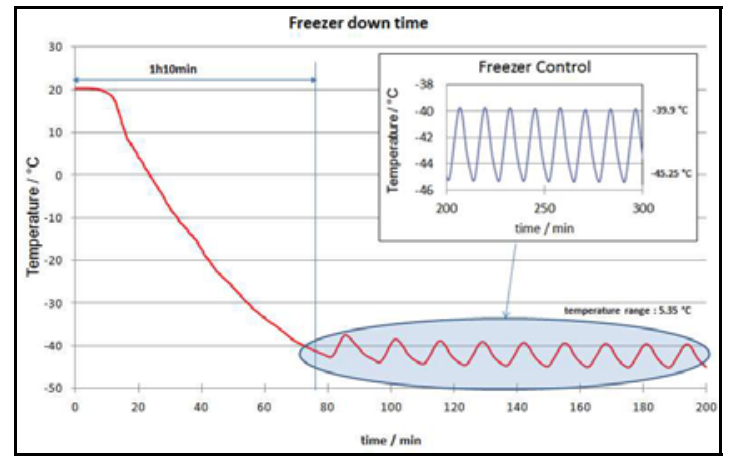

Fig. 8. Graphic representation of the thermal stability results obtained at $-45^{\circ} \mathrm{C}$

\subsection{Principle and instrumentation}

In the process of the heat pipe effect, it is important to control condensation of steam at the chimney (condenser) level. To guarantee this, it is necessary to condense all the ethanol at the condenser level in order to avoid that steam invades control circuit. To guarantee this, we used an alcohol stirred bath, with external circulation of fluid, set at temperature of $-20{ }^{\circ} \mathrm{C}$.

During the thermal characterization, all thermometers have been moved simultaneously and their positions controlled with great care.

First stage of the characterization work consists in finding the best relationship between the desired temperature, in the inner part, and the heating power for ensuring the widest adiabatic zone as possible. For this purpose, the saturation vapour curve of the working fluid, here the ethanol, is very helpful and useful. In order to check the settings, a thermal profile along the vertical axis is performed. To do this, Standard Platinum Resistance Thermometer (RTD) is used. The pressure and condensation's temperature are optimized to obtain the best thermal profile. Our criteria about the settings rely on the axial homogeneity which should be lower than $5 \mathrm{mK}$ over a length of $200 \mathrm{~mm}$. These results make it possible to conclude on the achievement of the heat pipe effect or not.

The GCHP characterization started in the same conditions as when calibrating industrial probes. For these measurements we didn't used thermal coupling, such as thermal grease or paste. For this study, nine calibrated RTD are used. Two types of RTD sensors are used, all of them with the same diameter of $6 \mathrm{~mm}$ but six with a sheath of $50 \mathrm{~mm}$ and three with a sheath of 200 $\mathrm{mm}$ length. This makes it possible to detect an immersion effect of the sensor sheaths. The results are presented in the next section, for three temperature levels: $+20^{\circ} \mathrm{C},-5^{\circ} \mathrm{C}$, and $-15^{\circ} \mathrm{C}$.

\subsection{Temperature profiles results (axial/vertical homogeneity)}

The axial homogeneity (thermal profile) of each thermos-wells was measured. To do this, the probes are lifted simultaneously by $20 \mathrm{~mm}$ in the axis of the well until the exit of the heat pipe. Only the reference probe remains at the bottom of the well to check the good thermal stability. The temperature of the latter must not vary by more than $5 \mathrm{mK}$. Before each measurement, a time of at least 20 minutes is used to ensure a good thermal stabilization. This time is necessary, especially for the measurements before the exit of the wells which require time before reaching thermal equilibrium.

The points plotted on the figures 9 and 10 correspond to the temperature difference between a reference temperature probe, set at the bottom of thermo-well, and the temperature probe along the vertical axis. The maximum value is used for plotting the curves.

Figure 9 shows an example of a thermal profile obtained at $20{ }^{\circ} \mathrm{C}$. The temperature is homogeneous over $260 \mathrm{~mm}$ of thermos-wells height in the heat pipe. The axial homogeneity is less than $5 \mathrm{mK}$. We can deduce that the heat pipe effect is present and thus the homogeneity is within $5 \mathrm{mk}$ over $260 \mathrm{~mm}$.

Nevertheless the homogeneity is about $20 \mathrm{mK}$ above $260 \mathrm{~mm}$. This is partly due to heat losses from the RTD probe sheaths with the external environment.

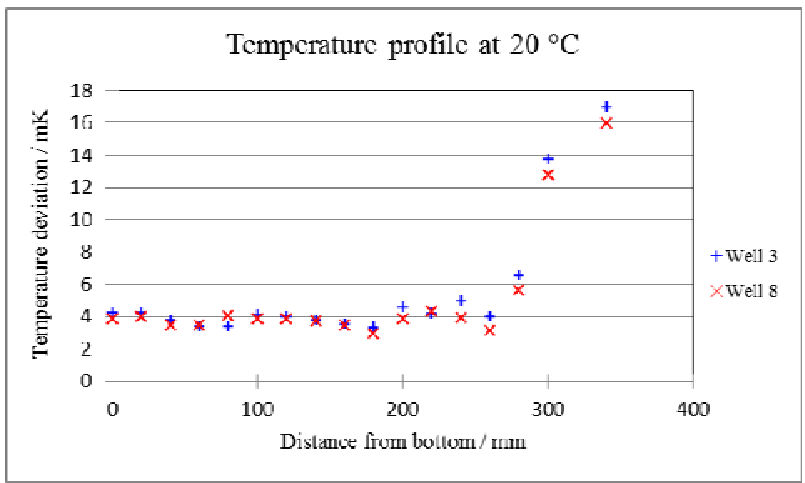

Fig. 9. Temperature profiles for two wells at $20{ }^{\circ} \mathrm{C}$

On figure 10 , we see the temperature profile at $-15^{\circ} \mathrm{C}$. The homogeneity is not sufficient. It is greater than $5 \mathrm{mK}$ beyond $200 \mathrm{~mm}$ from the bottom. After $120 \mathrm{~mm}$ it exceeds $10 \mathrm{mK}$. In this case, there is no heat pipe effect. This phenomena is mainly due to the low temperature enclosure which influence strongly the GCHP because of its weak stability. This point will be improved later. 


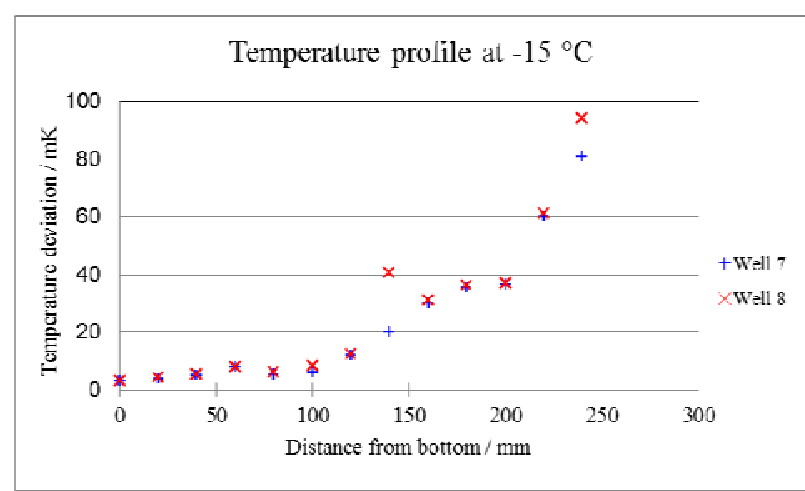

Fig. 10. Temperature profiles for two well à $-15^{\circ} \mathrm{C}$

\subsection{Radial temperature homogeneity results}

The radial homogeneity has been measured for three immersion depths: $0 \mathrm{~mm}, 50 \mathrm{~mm}$ and $100 \mathrm{~mm}$. The radial homogeneity is based on transposition method of measurement also known as Gauss double weighing method. The results for each temperature level are presented in figure 11 . The radial homogeneity observed varies from $1 \mathrm{mK}$ to $181 \mathrm{mK}$. The results depend on the temperature and immersion of the sensors. For the set points of $-5{ }^{\circ} \mathrm{C}$ and $-15^{\circ} \mathrm{C}$ the heat pipe effect was not optimal. The results presented correspond to the maximum temperature difference observed over at least 20 minutes.

Table 1. Summary table of lateral homogeneity.

\begin{tabular}{|c|c|c|c|}
\hline $\begin{array}{c}\text { homogeneity } \\
(\mathrm{mK})\end{array}$ & $\begin{array}{c}0 \mathrm{~mm} \\
(\text { Bottom })\end{array}$ & $50 \mathrm{~mm}$ & $100 \mathrm{~mm}$ \\
\hline At $20^{\circ} \mathrm{C}$ & 1 & 2 & 11 \\
\hline At $-5^{\circ} \mathrm{C}$ & 0 & 71 & 181 \\
\hline At $-15^{\circ} \mathrm{C}$ & 19 & 49 & 29 \\
\hline
\end{tabular}

These results (table 1) are satisfactory for $20^{\circ} \mathrm{C}$. For the others temperatures the heat pipe effect is not well establish which lead to such discrepancies. As a matter of fact, the weak stability of the low temperature enclosure could explain this observation.

In the next phase of this study, performances, namely stability, of the low temperature enclosure will be improved.

\subsection{Temperature stability results}

At last temperature stability has been checked during the experiment. According to table 2, the stability is better than $7 \mathrm{mK}$ for about one hour. This result could be affected by pressure controller's performances and again low temperature enclosure.

The table 2 below shows the results obtained for three temperature levels and for all the thermos-wells tested. For these measurements the acquisition time is twenty minutes.
Table 2. Summary table of thermal stability.

\begin{tabular}{|c|c|c|c|}
\hline $\begin{array}{c}\text { Stability } \\
(\mathrm{mK})\end{array}$ & $\begin{array}{c}0 \mathrm{~mm} \\
(\text { Bottom })\end{array}$ & $50 \mathrm{~mm}$ & $100 \mathrm{~mm}$ \\
\hline At $20^{\circ} \mathrm{C}$ & 5 & 5 & 6 \\
\hline At $-5^{\circ} \mathrm{C}$ & 6 & 6 & 7 \\
\hline At $-20^{\circ} \mathrm{C}$ & 5 & 5 & 6 \\
\hline
\end{tabular}

The stability seems not to be affected by the temperature level of the GCHP. The results obtained for thermal stability are consistent with our objective. This result is encouraging, as stability is an important component in the overall uncertainty budget.

\section{CONCLUSION}

Despite a characterization is still under process, temperatures range from $+20^{\circ} \mathrm{C}$ to $-15^{\circ} \mathrm{C}$ has been investigated. It comes that the stability is in accordance with the initial objective of $5 \mathrm{mK}$. At $20{ }^{\circ} \mathrm{C}$ the temperature profile is better than $5 \mathrm{mK}$ over $260 \mathrm{~mm}$ length. The temperature profile and the radial homogeneity at $-5^{\circ} \mathrm{C}$ and $-15^{\circ} \mathrm{C}$ do not meet our objectives. It seems that the main reason comes from the low temperature enclosure whom thermal stability strongly affect GCHP behaviour, especially when decreasing the temperature.

\section{References}

1. K. D. Hill, M. Gotoh, "The vapour pressure of sodium between $660{ }^{\circ} \mathrm{C}$ and $962^{\circ} \mathrm{C}$ ", Metrologia, 33, pp. 49 (1996)

2. K. D. Hill, M. Gotoh, "The vapour pressure of caesium between $370{ }^{\circ} \mathrm{C}$ and $660^{\circ} \mathrm{C}$ ", Metrologia, 33, pp. 307 (1996)

3. J.O. Favreau et al., Implementation of water heat pipe at CETIAT, $13^{\text {th }}$ International Symposium on Temperature and Thermal Measurements in Industry and Science - TEMPMEKO, Zakopane (Poland), june 2016

4. P.D. Dunn and D.A. Reay, Heat Pipes, Pergamon Press, 1976

5. A. Merlone et al., 20 Years of progress in the use of gas-controlled heat pipes for thermodynamic measurements, 16th International Heat Pipe Conference (16th IHPC), Lyon (France), May 2012

6. P. Marcarino, A. Merlone, "Towards new temperature standards for contact thermometry above $660{ }^{\circ}$ C", Metrologia, 39, 4, 2002, 395-398

7. A. Merlone, R. Dematteis, P. Marcarino, "GasControlled Heat Pipes for Accurate Liquid-Vapor Transition Measurements", International Journal of Thermophysics, 24, 3, 2003, 695-712 